\title{
Digital Holography Study of the Inhibitory Effects of Polyaspartic Acid on the Anodic Dissolution of Inconel ${ }^{\circledR} 600$
}

\section{Yu SHAO, Jiaojiao QI, Boyu YUAN, Liang LI,* (1) and Chao WANG*}

Jiangsu Key Laboratory of Green Synthetic Chemistry for Functional Materials, School of Chemistry \& Materials Science, Jiangsu Normal University, Building 19, Shanghai Road 101, Tongshan New Area, XuZhou 21116, China

*Corresponding authors: lil@jsnu.edu.cn, wangc@jsnu.edu.cn

\begin{abstract}
Electrochemical methods were used in conjunction with digital holography to study the effects of an environmentally friendly inhibitor, polyaspartic acid (PASP), on the anodic dissolution of Inconel ${ }^{\circledR} 600$ in a $0.04 \mathrm{M} \mathrm{HCl}$ solution. The pitting inhibition ability was enhanced and the inhibition efficiency increased with the PASP concentration, reaching $84.13 \%$ at $6.66 \mathrm{~g} \mathrm{~L}^{-1}$ PASP. A digital holograph was used to observe the in situ hydrolysis of $M^{2+}(M=$ $\mathrm{Ni}$ and $\mathrm{Fe}$ ) near the electrode surface during anodic dissolution and showed the formation of a surface film on the electrode. The inhibitory effects of PASP on Inconel ${ }^{\circledR} 600$ may be caused by the adsorption of PASP and the formation of a PASP metal complex (PASP-M complex), which may seal defects in the surface film.
\end{abstract}

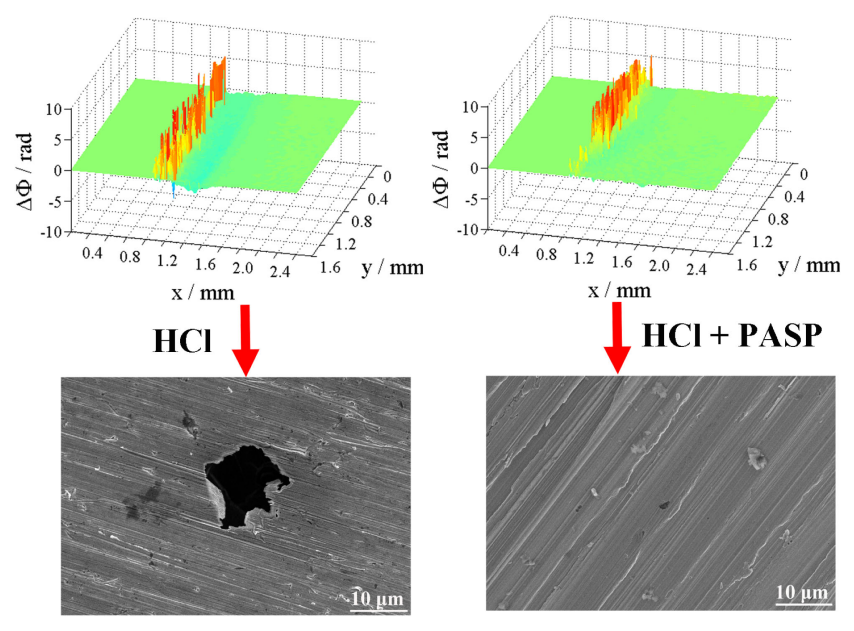

(C) The Author(s) 2021. Published by ECSJ. This is an open access article distributed under the terms of the Creative Commons Attribution 4.0 License (CC BY, http://creativecommons.org/licenses/by/4.0/), which permits unrestricted reuse of the work in any medium provided the original work is properly cited. [DOI: 10.5796/electrochemistry.21-00021].

Keywords : Inconel ${ }^{\circledast}$ 600, Polyaspartic Acid, Inhibitor, Digital Holography

\section{Introduction}

Inconel ${ }^{\circledR} 600$ is a nickel-based alloy with high temperature stability, good corrosion resistance, and high pressure resistance that is often used to make heat transfer tubes for steam generators in nuclear power plants. ${ }^{1-5}$ Numerous corrosion products and dirt accumulated inside pipelines affect the heat exchange performance of the pipeline and cause pipeline corrosion leakage, resulting in equipment accidents and economic losses. Pipelines must be regularly cleaned to prevent these hazards. The acidic solutions, such as sulphuric and hydrochloric acids, that are generally used to clean and descale pipelines can corrode pipelines easily. ${ }^{6}$ Therefore, it is necessary to add inhibitors to pickling solutions. ${ }^{7,8}$

Nitrates, nitrites, chromates, and dichromates are often used as corrosion inhibitors in traditional acidic pickling solutions. ${ }^{9}$ Nitrates and dichromates are well-known environmental pollutants. ${ }^{10}$ Synthetic organic compounds are also used as inhibitors, but have limited use, being potential human health hazards and environmental pollutants. ${ }^{11}$ Therefore, green inhibitors are needed to replace harmful inhibitors. M. Abdallah et al. ${ }^{12}$ used potentiodynamic polarization to study the inhibitory effects of natural clove oil on the corrosion of Inconel ${ }^{\circledR} 600$; however, relatively few studies have been conducted on the effects of environmentally friendly inhibitors on the corrosion of Inconel ${ }^{\circledR} 600$.

Polyaspartic acid (PASP) is a natural amino acid with a carboxyl side chain that occurs in animals and is nontoxic, biodegradable, and

L. Li (DD) orcid.org/0000-0001-8983-6098 environmentally friendly. Gao et al. ${ }^{8}$ used electrochemical and weight loss methods to study the inhibitory effects of a PASP derivative on the corrosion of carbon steel in seawater and reported an inhibition efficiency of $95 \%$. Wang et al. ${ }^{13}$ reported an inhibition efficiency of up to $94.48 \%$ by a prepared PASP-Zn film. Zeino et al. ${ }^{14}$ used electrochemical, thermodynamic, microscopic and computational chemistry techniques to investigate the inhibitory mechanism of PASP on mild steel in a $\mathrm{NaCl}$ solution and reported that the synergistic effect between added zinc ions and PASP resulted in an efficiency of up to $97 \%$. Yang et al. ${ }^{15}$ used electrochemical impedance spectroscopy to investigate the inhibitory effects of PASP on a magnesium alloy in a $\mathrm{NaCl}$ solution and reported a maximum efficiency of $94.2 \%$. PASP is widely used as an inhibitor for various metallic materials; however, relatively few studies have been conducted on the inhibitory effects of PASP on the corrosion of Inconel ${ }^{\circledR} 600$.

Various methods have been used to study the corrosion of metallic materials, such as electrochemical methods, electrochemical impedance, weight-loss methods, SEM (scanning electronic microscopy), and EDS (Energy Dispersive Spectrometer); however, these methods cannot be used to observe the dynamic processes at the electrode/electrolyte interface in situ. Digital holography, an online technology with high temporal resolution, ${ }^{16,17}$ has been used in recent years to observe the dynamic processes at the electrode|electrolyte interface in situ during the anodic dissolution of metallic materials. Anodic dissolution of Inconel ${ }^{\circledR} 600$ in solutions with and without inhibitors has been further explored using online techniques to observe dynamic processes at the interface. 
Digital holography was used in this study to observe the anodic dissolution of Inconel ${ }^{\circledR} 600$ in $\mathrm{HCl}$ solution in situ without and with PASP. SEM was used to observe the surface morphology of Inconel ${ }^{\circledR} 600$ before and after anodic dissolution, and the surface composition was analysed by EDS. The electrochemical results, phase maps, surface morphologies, and surface composition are used to analyse the inhibitory effects of PASP.

\section{Experimental}

\subsection{Electrochemical measurements}

A three-electrode system was used to perform an electrochemical test. The working electrode was made of Inconel ${ }^{\circledR} 600(d=2 \mathrm{~mm}$, Cr: $15.5 \%$, Fe: $8 \%$, Mn: $1.0 \%$, Cu: $0.5 \%$, Si: $0.5 \%$, C: $0.15 \%$, S: $0.01 \%$, Ni: balance; Goodfellow Inc.) embedded in epoxy resin, where only the surface (with a circular cross section) was exposed to the solution. The electrode surface was placed sideways in a vertical orientation. The counter and reference electrodes were platinum sheet $(10 \mathrm{~mm} \times 10 \mathrm{~mm})$ and saturated calomel electrode (SCE), respectively. A Luggin capillary was used between the working and reference electrodes to minimize the IR drop. Before each experiment was conducted, the working electrode was polished with 600 , 1200, and 2000 metallographic sandpaper, cleaned with doubly distilled water and ethanol in an ultrasonic bath, and then immersed in the acidic solution for 10 min to maintain a stable open circuit potential (OCP). The electrochemical experiments were carried out with a CHI660E electrochemical workstation. The Tafel plot had a scan rate of $1 \mathrm{mV} \mathrm{s}^{-1}$. All the experiments were carried out at room temperature. All the solutions used in the experiment were prepared with analytical reagents and doubly distilled water. The structure of PASP (Analytical Reagent, Relative molecular mass, $\mathrm{Mr}=3000$ 5000) is shown in Fig. 1.

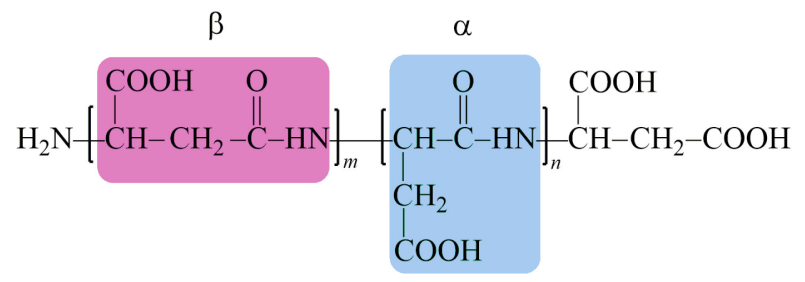

Figure 1. Chemical structure of PASP.

\subsection{Holographic recording system}

Figure 2 illustrates the holographic system, which we used in a previous study. ${ }^{18}$ The light from a $\mathrm{He}-\mathrm{Ne}$ laser (wavelength: $632.8 \mathrm{~nm}$ ) was refracted by $\mathrm{M}$ (the refractor) and then split into two beams by BS (the beam splitter): an object wave and a reference wave. The object wave passed through EC (the electrochemical cell, $\mathrm{W}$-working electrode; R-reference electrode; C-counter electrode), which interfered with the reference wave at a CCD image sensor, and the interference fringes were recorded by a computer. When there were the concentrations gradients of the soluble species $(\Delta c)$ in the solution near the electrode surface during the anodic dissolution processes, a refractive index gradients $(\Delta n)$ gave rise to the interference fringes (shown in the computer) and phase difference $(\Delta \Phi)$. We wrote software to reconstruct phase maps from the interference fringes, and reconstruction processes are referred to the reference. ${ }^{18}$ Equation (1) relates $\Delta \Phi, \Delta n$, and $\Delta c:{ }^{19}$

$$
\Delta c=k \Delta n=k \lambda_{0} \Delta \Phi / 2 \pi d
$$

where $k, \lambda_{0}$, and $d$ are the concentrative refractivity, the light wavelength, and the geometrical path length, respectively, in the presence of a variation in the refractive index.

\subsection{SEM and EDS}

After completion of the electrochemical test, the electrode was cleaned with distilled water and ethanol twice in an ultrasonic bath for 2 min; SEM (Hitachi S-3400N) was then used to observe the surface morphology of the electrode. The composition of the electrode surface was analysed by EDS.

\section{Results and Analysis}

\subsection{Tafel plots}

Figure 3 shows the Tafel curves for Inconel ${ }^{\circledR} 600$ in $0.04 \mathrm{M}$ $\mathrm{HCl}+x \mathrm{gL}^{-1}$ PASP $(x=0,0.13$, and 6.66) solutions. As shown in Fig. 3, the cathodic current changes slightly as the PASP concentration $\left(c_{\text {PASP }}\right)$ increases. The anodic polarization curve can be divided into three potential regimes: the current increases with the potential up to a peak, which indicates an active regime for the potential; beyond the current peak, positive shifts in the potential cause the current to decrease, indicating the formation of a surface film; after the film is broken in the presence of aggressive ions $\left(\mathrm{H}^{+}\right.$ and $\mathrm{Cl}^{-}$), the electrode is reactivated. In each potential regime, the

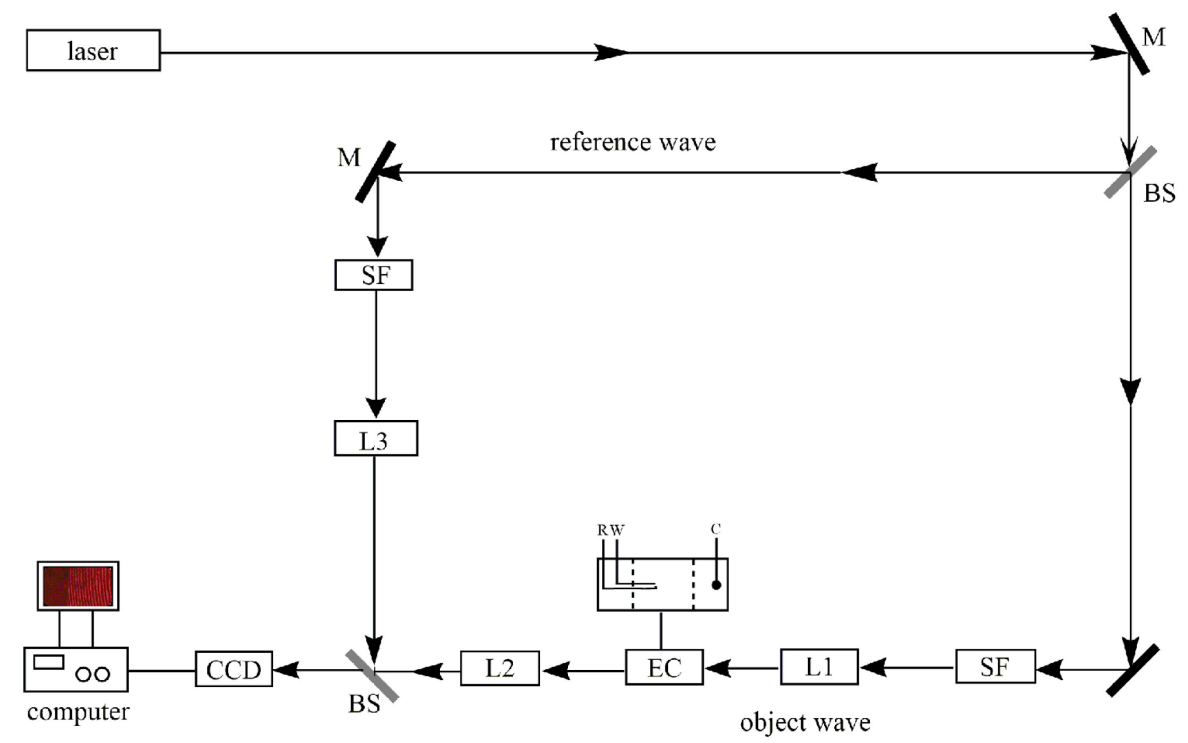

Figure 2. The experimental setup of the digital holographic surface imaging system and the schematic diagram of the electrochemical cell (EC, W-working electrode; R-reference electrode; C-counter electrode). M - mirror, BS - beam splitter, L1-L3 - collimating lens, SF - spatial filter. 


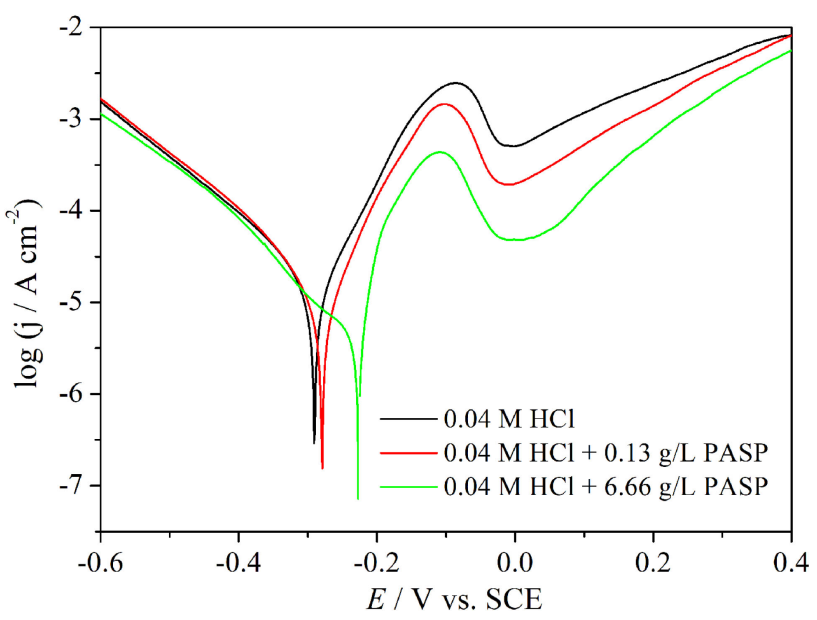

Figure 3. The Tafel curves of Inconel ${ }^{\circledR} 600$ in $0.04 \mathrm{M} \mathrm{HCl}+$ $x \mathrm{~g} \mathrm{~L}^{-1}$ PASP $\left(x=0,0.13\right.$, and 6.66) solutions. Scan rate: $1 \mathrm{mV} \mathrm{s}^{-1}$.

Table 1. The parameters obtained from the Tafel plots shown in Fig. 2.

\begin{tabular}{ccccccc}
\hline $\begin{array}{c}c_{\text {PASP }} / \\
\mathrm{g} \mathrm{L}^{-1}\end{array}$ & $E_{\text {corr }} / \mathrm{V}$ & $\begin{array}{c}j_{\text {corr }} / \\
\mu \mathrm{A} \mathrm{cm}^{-2}\end{array}$ & $\eta / \%$ & $E_{\text {peak }} / \mathrm{V}$ & $\begin{array}{c}j_{\text {peak }} / \\
\mathrm{mAcm}^{-2}\end{array}$ & $\begin{array}{c}-b_{\mathrm{c}} / \\
\mathrm{mV}\end{array}$ \\
\hline 0 & -0.2885 & 26.90 & $/$ & -0.084 & 2.46 & 154.4 \\
0.13 & -0.2814 & 15.96 & 40.67 & -0.102 & 1.46 & 139.1 \\
6.66 & -0.2268 & 4.27 & 84.13 & -0.111 & 0.434 & 128.4 \\
\hline
\end{tabular}

anodic current decreases with increasing $c_{\mathrm{PASP}}$, indicating that PASP can inhibit corrosion.

The inhibition efficiency $\eta$ was calculated as shown in Eq. (2):

$$
\eta=\frac{j_{\text {corr }}^{0}-j_{\text {corr }}}{j_{\text {corr }}^{0}} \times 100 \%
$$

where $j_{\text {corr }}^{0}$ and $j_{\text {corr }}$ are the corrosion currents of the electrodes in a $0.04 \mathrm{M} \mathrm{HCl}$ solution without and with PASP, respectively. The corrosion parameters were obtained by cathodic Tafel fitting only because the anodic branch did not exhibit any Tafel characteristics. The parameters obtained from the Tafel curves (Fig. 3) are presented in Table 1. As shown in Table 1 and Fig. 3, increasing $c_{\text {PASP }}$ results in a positive shift in the corrosion potential $\left(E_{\text {corr }}\right)$ and an increase in $\eta$ but in a negative shift in the peak potential $\left(E_{\text {peak }}\right)$ and a decrease of the peak current $\left(j_{\text {peak }}\right)$. The highest $\eta$ of $84.13 \%$ is obtained at $6.66 \mathrm{~g} \mathrm{~L}^{-1}$ PASP.

\subsection{Polarization curves and corresponding phase maps}

The upper part of Fig. 4 shows the anodic polarization curves of Inconel ${ }^{\circledR} 600$ in $0.04 \mathrm{M} \mathrm{HCl}+x \mathrm{~g} \mathrm{~L}^{-1} \mathrm{PASP}(x=0,0.13$, and 6.66) solutions obtained at a scan rate of $10 \mathrm{mV} \mathrm{s}^{-1}$, and it shows that the current decreases with increasing $c_{\text {PASP. }}$ The lower part of Fig. 4 shows the phase maps at different potentials corresponding to b-e in the polarization curves. As shown in the phase maps, the same English letter means the same potential, for example, Figs. $4 b, 4 b^{\prime}$, and $4 b^{\prime \prime}$ are the images obtained at the potential corresponding to point $\mathrm{b}$ in $0.04 \mathrm{M} \mathrm{HCl}, 0.04 \mathrm{M} \mathrm{HCl}+0.13 \mathrm{~g} \mathrm{~L}^{-1} \mathrm{PASP}$, and $0.04 \mathrm{M}$ $\mathrm{HCl}+6.66 \mathrm{~g} \mathrm{~L}^{-1}$ PASP solutions respectively shown in the upper part of Fig. 4.

Digital holography was used to observe the dynamic processes at the electrode|electrolyte interface in situ to investigate the anodic dissolution of the electrode in $\mathrm{HCl}$ solution. In Fig. 4, $X, Y$, and $Z$ represent the horizontal direction, the optical axis direction, and the opposing direction of gravity, respectively. Figures $4 a, 4 a^{\prime}$, and $4 a^{\prime \prime}$ are the images obtained at OCP in the solutions without, with
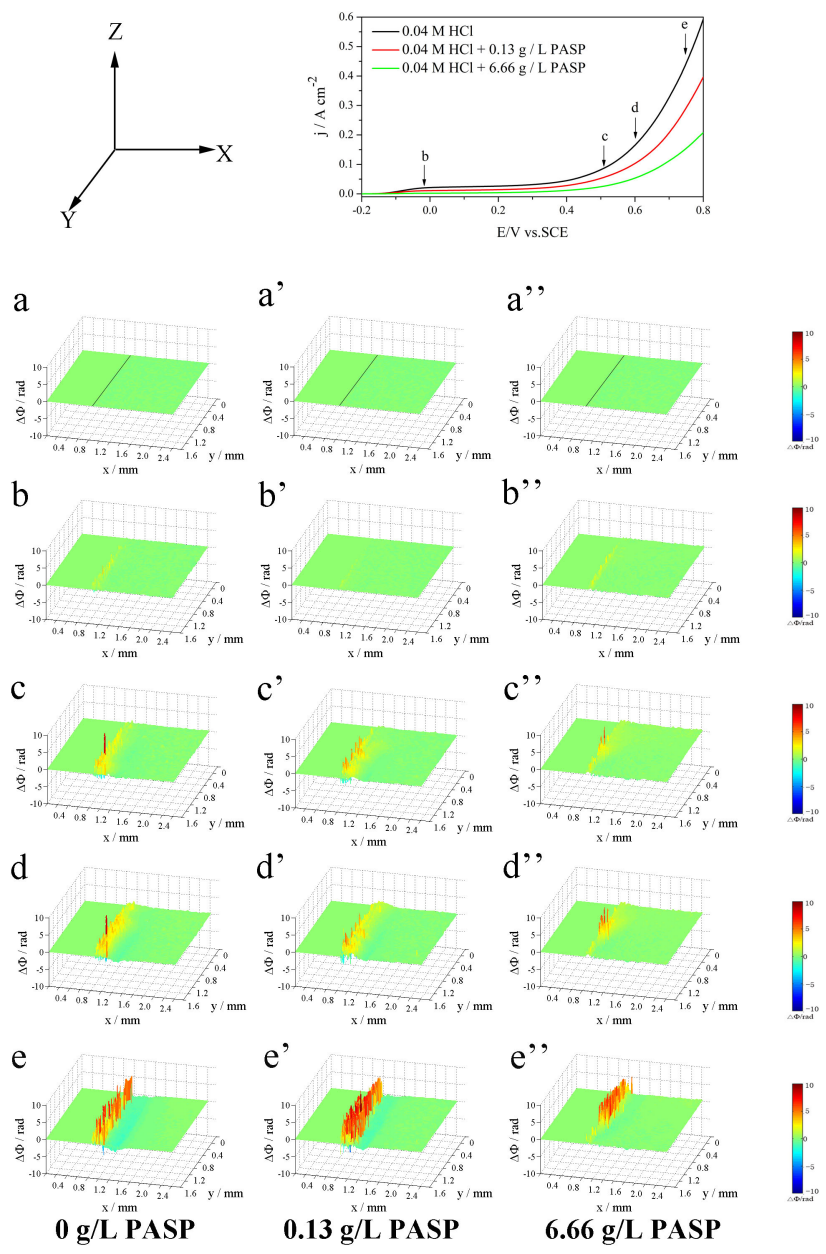

Figure 4. The polarization curve (upper part) of Inconel ${ }^{\circledR} 600$ in $0.04 \mathrm{M} \mathrm{HCl}+x \mathrm{~g} \mathrm{~L}^{-1}$ PASP $(x=0,0.13$, and 6.66$)$ at $10 \mathrm{mV} \mathrm{s}^{-1}$ and the phase reconstruction maps (lower part) at different potentials corresponding to points $\mathrm{b}-\mathrm{e}$ in the polarization curve, $\mathrm{a}, \mathrm{a}^{\prime}$, and $\mathrm{a}^{\prime \prime}$ in the lower part: the images obtained at the open circuit potential in $0.04 \mathrm{M} \mathrm{HCl}, 0.04 \mathrm{M} \mathrm{HCl}+0.13 \mathrm{gL}^{-1}$, and $0.04 \mathrm{M} \mathrm{HCl}+6.66$ $\mathrm{gL}^{-1}$ PASP respectively. $X$ - horizontal direction, $Y$ - gravity direction in reverse, and $Z$ - phase difference and optical axis direction.

$0.13 \mathrm{~g} \mathrm{~L}^{-1}$, and $6.66 \mathrm{~g} \mathrm{~L}^{-1}$ PASP respectively and the position of the electrode/electrolyte interface is marked with a black line. The right and left sections of each phase map correspond to the electrolyte and the electrode, respectively. The colour in each phase map is related to the concentration change $(\Delta c)$. The relationship between the phase difference $(\Delta \Phi), \Delta c$, and the colour of the phase map is discussed as follows. If $\Delta \Phi>0$, then $\Delta c>0$, and the phase map is red and/or yellow, indicating an increase in the concentration; if $\Delta \Phi=0$, then $\Delta c=0$, and the phase map is green, indicating little change in the concentration; if $\Delta \Phi<0$, then $\Delta c<0$, and the phase map is blue, indicating that the concentration decreases and is lower at the interface than in the bulk solution.

As shown in the lower part of Fig. 4, at the initial stage, the shallow yellow areas at the interface in $0.04 \mathrm{M} \mathrm{HCl}$ (Fig. 4b), $0.04 \mathrm{M} \mathrm{HCl}+0.13 \mathrm{~g} \mathrm{~L}^{-1}$ PASP (Fig. 4b'), and $0.04 \mathrm{M} \mathrm{HCl}+6.66$ $\mathrm{gL}^{-1}$ PASP solutions (Fig. $4 \mathrm{~b}^{\prime \prime}$ ) show that the electrode is beginning to dissolve. As the potential increases to points $\mathrm{c}$ and $\mathrm{d}$ in the polarization curves, the currents increase and the yellow regions at the interface continue to extend in the solutions without (Figs. $4 \mathrm{c}$ and $4 \mathrm{~d}$ ), with $0.13 \mathrm{~g} \mathrm{~L}^{-1}$ (Figs. $4 \mathrm{c}^{\prime}$ and $4 \mathrm{~d}^{\prime}$ ), and $6.66 \mathrm{~g} \mathrm{~L}^{-1}$ PASP (Figs. $4 \mathrm{c}^{\prime \prime}$ and $4 \mathrm{~d}^{\prime \prime}$ ), respectively, indicating that the 
concentration at the interface increases with the current. As the potential increases to point $\mathrm{e}$, the currents continue to increase and there are two regions at the interface in the solutions without (Fig. 4e) and with $0.13 \mathrm{~g} \mathrm{~L}^{-1}$ PASP (Fig. 4e'): red/yellow region (inner) and a blue region (outer); however, the blue one is not distinct in solution with $6.66 \mathrm{~g} \mathrm{~L}^{-1}$ PASP (Fig. 4e $\mathrm{e}^{\prime \prime}$ ). The dissolved metal ions increases the concentration at the interface causing an increase in the refractive index, and then the phase difference becomes positive (red/yellow region), while the consumption of the metal ions to form the oxide film leads an opposing way (the blue region).

\section{$3.3 j$ - $t$ curves and corresponding phase maps}

Figure 5 shows the $j$ - $t$ curves (upper part) at $0.4 \mathrm{~V}$ and the phase maps at different times (lower part) corresponding to $\mathrm{b}-\mathrm{d}$ in the $j-t$ curves. In the phase maps, the same English letter means the same times in the $j$ - $t$ curves. As time goes on in the $j$ - $t$ curves, the current increases in the solution without PASP; however, it decreases in the solution with $0.13 \mathrm{~g} \mathrm{~L}^{-1}$ or $6.66 \mathrm{~g} \mathrm{~L}^{-1}$ PASP. The current is highest in the solution without PASP and lowest in the solution with $6.66 \mathrm{~g} \mathrm{~L}^{-1}$ PASP.

Figure $5 \mathrm{a}, 5 \mathrm{a}^{\prime}$ and $5 \mathrm{a}^{\prime \prime}$ are also obtained at OCP in solutions without and with PASP, and the details of the phase maps shown in Fig. 5 are illustrated as follow. The phase maps show that the concentration at the interface increases in the solution without PASP (Fig. 5b), reflecting the beginning of the dissolution of the electrode. However, the diffusion layer is much thinner and the concentration

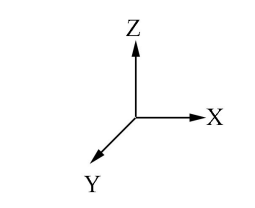

a
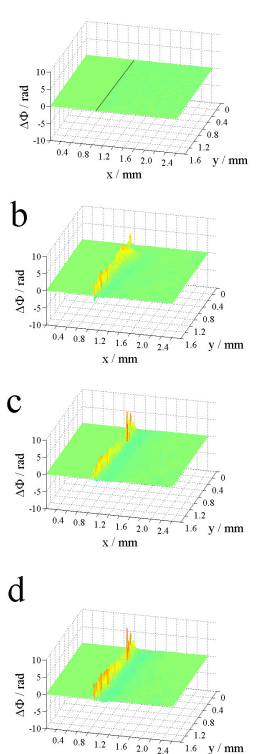

0 g/L $/$ PASP

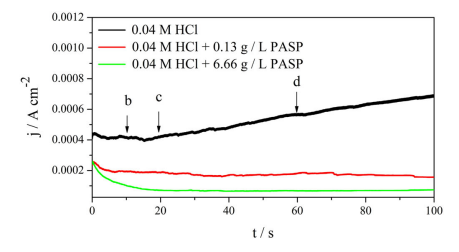

$a^{\prime}$
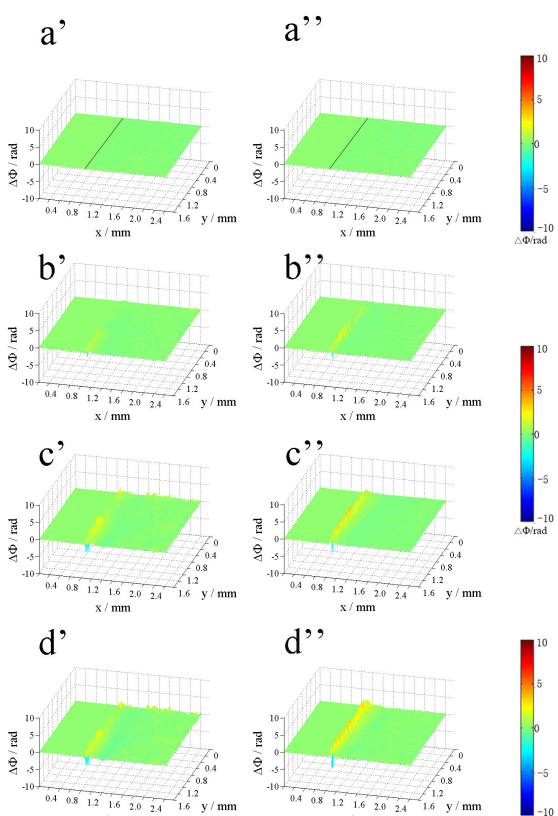

$0.13 \mathrm{~g} / \mathrm{L} / \mathrm{L}$ PASP
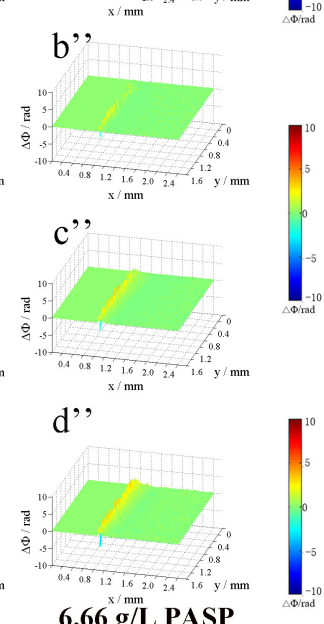

Figure 5. The $j$ - $t$ curves of Inconel ${ }^{\circledR} 600$ in $0.04 \mathrm{M} \mathrm{HCl}+x \mathrm{~g} \mathrm{~L}^{-1}$ PASP $(x=0,0.13$, and 6.66) solutions at $0.4 \mathrm{~V}$ and the phase reconstruction maps (lower part) at different time corresponding to points $b-d$ in the $j-t$ curves, a, $a^{\prime}$, and $a^{\prime \prime}$ in the lower part: the images obtained at the open circuit potential in $0.04 \mathrm{M} \mathrm{HCl}, 0.04 \mathrm{M}$ $\mathrm{HCl}+0.13 \mathrm{~g} \mathrm{~L}^{-1}$, and $0.04 \mathrm{M} \mathrm{HCl}+6.66 \mathrm{~g} \mathrm{~L}^{-1}$ PASP respectively. $X$ - horizontal direction, $Y$ - gravity direction in reverse, and $Z$ phase difference and optical axis direction. near the electrode surface is much lower in the solution with $0.13 \mathrm{gL}^{-1}$ (Fig. 5b') or $6.66 \mathrm{gL}^{-1}$ PASP (Fig. 5b") than that without PASP (Fig. 5b). As time goes on to point c, there are two layers at the interface in the solution without PASP (Fig. 5c): the concentration increasing at the inner layer but decreasing at the outer layer. However, it increases only near the surface of the electrode in the solution with $0.13 \mathrm{gL}^{-1}$ (Fig. $5 \mathrm{c}^{\prime}$ ) or $6.66 \mathrm{gL}^{-1}$ PASP (Fig. $5 \mathrm{c}^{\prime \prime}$ ), respectively. At point $d$, there are also two layers at the interface in the solutions without PASP (Fig. 5d) and with $0.13 \mathrm{~g} \mathrm{~L}^{-1}$ PASP (Fig. 5 $\mathrm{d}^{\prime}$ ); however, this phenomenon is not yet observed in the solution with $6.66 \mathrm{~g} \mathrm{~L}^{-1}$ PASP (Fig. $5 \mathrm{~d}^{\prime \prime}$ ).

\subsection{Surface analysis}

After anodic dissolution for $100 \mathrm{~s}$ at $0.4 \mathrm{~V}$, the surface morphologies of the electrodes were observed (Fig. 6). The electrode exhibits a relatively smooth surface before the test (Figs. 6A and 6A1) but is severely corroded after anodic dissolution in solutions without PASP (Figs. 6B and 6B1) and with $0.13 \mathrm{~g} \mathrm{~L}^{-1}$ (Figs. 6C and 6C1) PASP. To show the pits more clearly, a red circle is marked around a pit. It shows clearly that the number of pits is much more in solution without PASP (Fig. 6B) than that with $0.13 \mathrm{~g} \mathrm{~L}^{-1}$ (Fig. 6C) PASP, and both the radius and the depth of the pit in the solution without PASP (Fig. 6B1) is much larger than those shown in the solution with $0.13 \mathrm{~g} \mathrm{~L}^{-1}$ PASP (Fig. 6C1), indicating that PASP inhibits pitting corrosion to some extent even though its concentration is as low as $0.13 \mathrm{~g} \mathrm{~L}^{-1}$. By contrast, few pits (Fig. 6D) but corrosion products are observed in the solution with $6.66 \mathrm{~g} \mathrm{~L}^{-1}$ PASP (Fig. 6D1), indicating inhibition of pitting corrosion at the highest level at this PASP concentration.

The chemical composition of the electrode surfaces shown in Figs. $6 \mathrm{~B} 1$ and $6 \mathrm{D} 1$ in the solutions without and with $6.66 \mathrm{~g} \mathrm{~L}^{-1}$
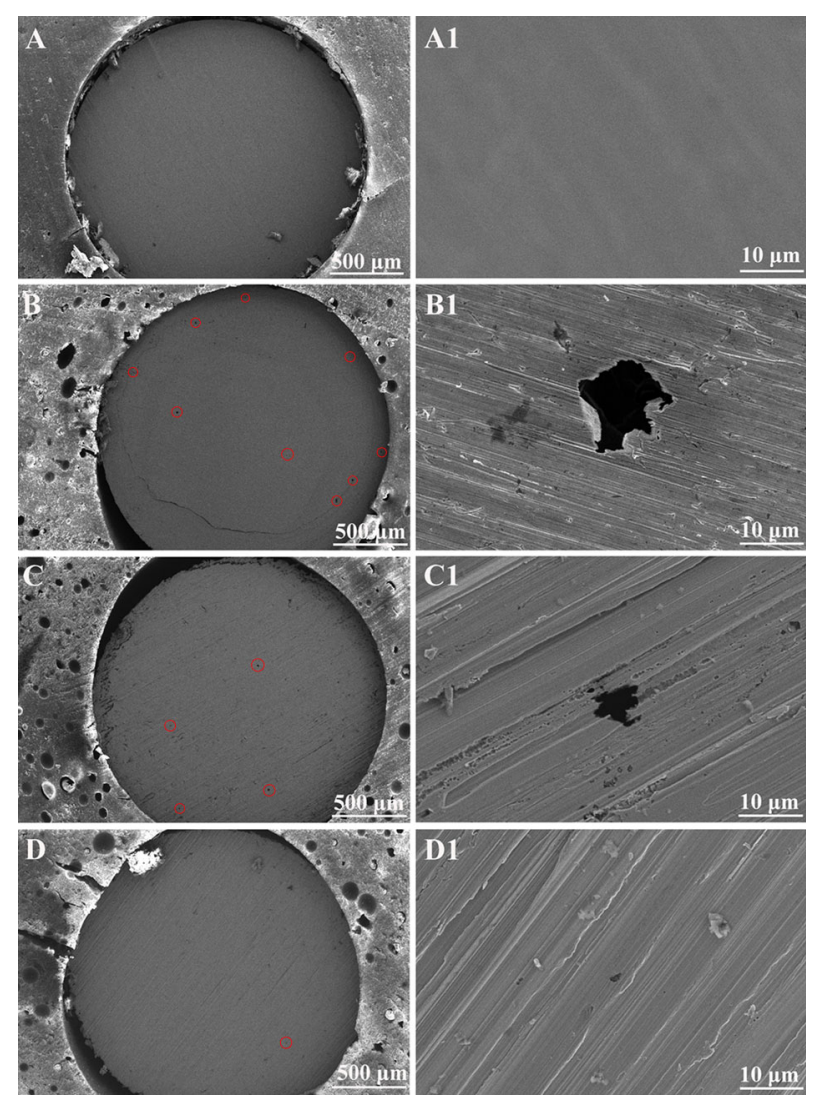

Figure 6. Surface morphologies of Inconel ${ }^{\circledR} 600$ recorded before (A and $\mathrm{A} 1$ ) and after potentiostatic polarization at $0.4 \mathrm{~V}$ for $100 \mathrm{~s}$ in $0.04 \mathrm{M} \mathrm{HCl}$ (B and B1), $0.04 \mathrm{M} \mathrm{HCl}+0.13 \mathrm{gL}^{-1}$ (C and $\mathrm{C} 1$ ), and $0.04 \mathrm{M} \mathrm{HCl}+6.66 \mathrm{~g} \mathrm{~L}^{-1}$ PASP (D and D1) solutions, respectively. 

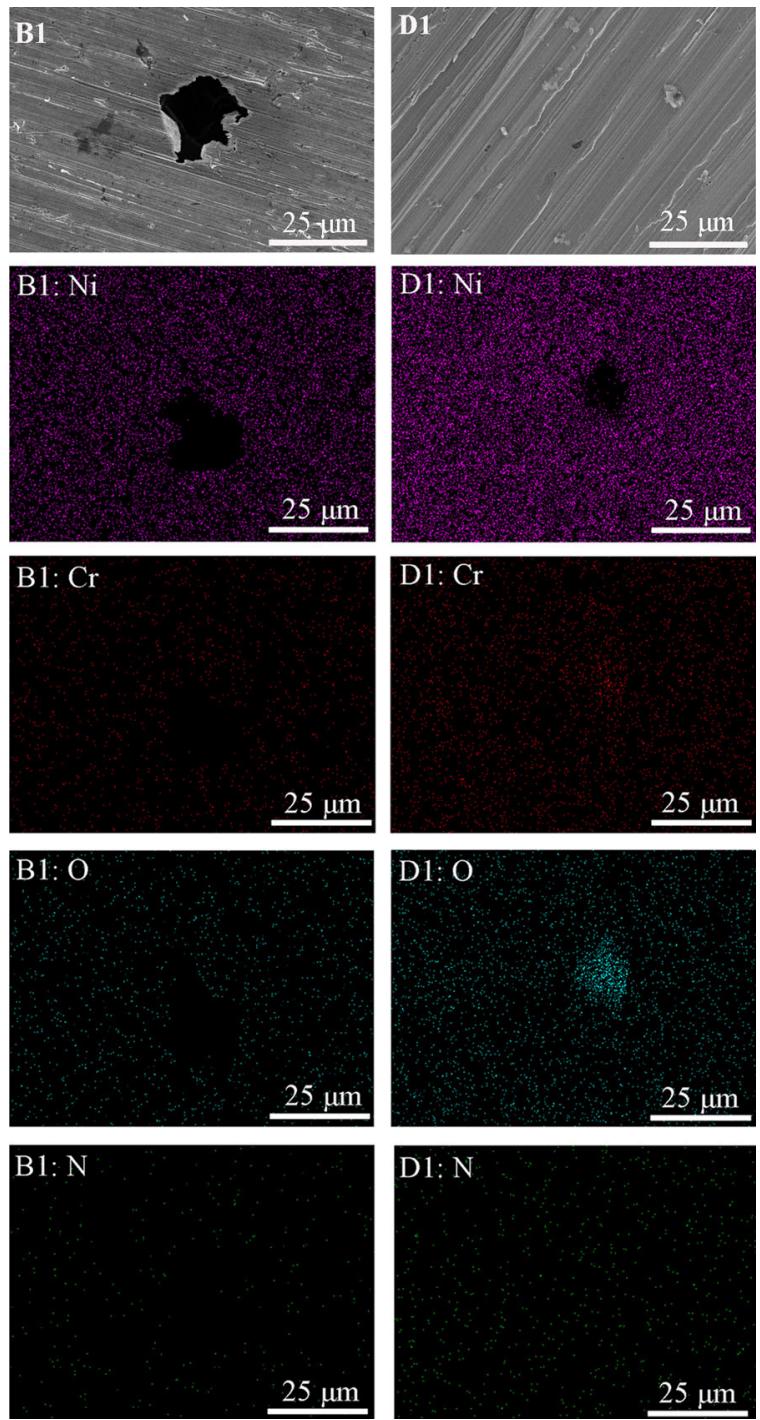

Figure 7. Surface morphologies of Inconel ${ }^{\circledR} 600$ after potentiostatic polarization in $0.04 \mathrm{M} \mathrm{HCl}(\mathrm{B} 1)$ and $0.04 \mathrm{M} \mathrm{HCl}+6.66 \mathrm{~g} \mathrm{~L}^{-1}$ (D1) solutions respectively and the corresponding EDS results of the surface.

PASP has been measured by EDS. Figure 7 demonstrates EDS results of the sample corresponding to Figs. 6B1 and 6D1. The contents of $\mathrm{Ni}, \mathrm{Cr}, \mathrm{O}$, and $\mathrm{N}$ are detected in Figs. 7B1 and 7D1. After anodic dissolution of the electrode in solution with $6.66 \mathrm{~g} \mathrm{~L}^{-1}$ PASP (Fig. 7D1), the content of $\mathrm{O}$ is much higher at the position of the corrosion products (Fig. 6D1) than the other areas, and it is also much higher than that in solution without PASP (Fig. 7B1).

\section{Discussion}

As shown in Fig. 3, as the PASP concentration ( $\left.c_{\mathrm{PASP}}\right)$ increased, the cathodic current changed slightly, whereas the anodic current decreased, indicating that PASP affected the cathodic reaction little, and it shows that PASP was an anodic inhibitor. The results in Table 1 and Fig. 3 show that $E_{\text {corr }}$ shifted positively and $\eta$ increased with $c_{\text {PASP }}$, indicating that PASP may adsorb on the electrode surface. $E_{\text {peak }}$ shifted negatively and $j_{\text {peak }}$ decreased, indicating that the surface film was formed more easily and it became denser with

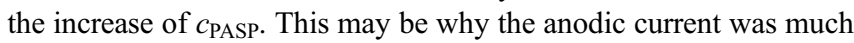
lower in the solution with PASP than that without PASP (Figs. 3-5) even though the applied potential was much higher than $E_{\text {corr }}$.

$$
\begin{aligned}
& M \rightarrow M^{2+}+2 \mathrm{e}^{-} \\
& M^{2+}+2 \mathrm{H}_{2} \mathrm{O} \rightarrow M(\mathrm{OH})_{2}+2 \mathrm{H}^{+}
\end{aligned}
$$

Two regions can be observed in the solutions without (Fig. 4e) and with $0.13 \mathrm{~g} \mathrm{~L}^{-1}$ (Fig. 4e') PASP: red and yellow regions (inner) and a blue region (outer) at the interface. The red and yellow regions indicate that the concentration at the interface increases. Generally, several components are present in the solution. The net refractive index is the summation of the effect of each species' concentration, as shown in Eq. (5).

$$
\sum_{i}\left(\Delta C_{i}\right)=\sum_{i} k_{i} \Delta n_{i}=\left(\lambda_{0} / 2 \pi \mathrm{d}\right) \sum_{i} k_{i} \Delta \phi_{i}
$$

During the anodic dissolution of the Inconel ${ }^{\circledR} 600$, the phase $\Delta \Phi$ reconstructed from the holograms, which is the sum of the phase difference caused by various species, cannot determine the individual concentration change $\Delta C_{i}$ of the species involved. In order to obtain qualitative information about the reactions, approximations can be made that allow some of the terms in the Eq. (1) to be neglected. However, eventually, candidate reaction mechanisms must be tested with a whole model to confirm that they agree with the experimental results. Because $\mathrm{Cr}$ helps to form a thin and tightly adhering oxide layer and the anodic current of $\mathrm{Cr}$ was about two orders of magnitude lower than that of $\mathrm{Fe}$ or $\mathrm{Ni}$ in the chloride ions containing solution, ${ }^{16}$ it is reasonable to deduce that the increase of the concentration at the interface maybe mainly caused by the diffusion of $M^{2+}(M=\mathrm{Ni}$ and $\mathrm{Fe}$; Eq. (3)) to the solution. The blue regions indicate a decrease in the concentration at the interface, which was caused by the consumption of the metal ions to form the oxide film. The details can be illustrated as follow: The currents are relatively higher in the solutions without and with $0.13 \mathrm{~g} \mathrm{~L}^{-1}$ PASP (upper part of Fig. 4) and the concentration increases at the inner layer but decreases at the outer layer (lower part of Fig. 4); therefore, many $M^{2+}$ ions (inner layer: yellow/red) are produced that repel $\mathrm{H}^{+}$ions near the electrode surface. ${ }^{20}$ As a result, the $\mathrm{pH}$ value at the interface increases, and $M^{2+}$ ions hydrolyse easily (Eq. (4)), decreasing the concentrations of ions at the interface (outer layer: blue). This phenomenon is much more obvious in the solution without PASP (Fig. 4e) than that with $0.13 \mathrm{~g} \mathrm{~L}^{-1}$ PASP (Fig. $4 \mathrm{e}^{\prime}$ ) because of the higher current. However, there is no distinct blue region in Fig. $4 \mathrm{e}^{\prime \prime}$ for the solution with $6.66 \mathrm{~g} \mathrm{~L}^{-1}$ PASP. This result may be explained by the following two reasons. On the one hand, the polarization curve in the upper part of Fig. 4 shows that the lowest anodic current is obtained in the solution with $6.66 \mathrm{~g} \mathrm{~L}^{-1}$ PASP; thus, relatively fewer ions are produced to repel $\mathrm{H}^{+}$ions near the electrode surface, and $M^{2+}$ ions cannot hydrolyse easily because of the low $\mathrm{pH}$ at the interface. On the other hand, the high PASP concentration may enable $M^{2+}$ ions to form complexes with PASP anions that can dissolve in the solution.

This hypothesis is verified by the results shown in Fig. 5, where the blue regions were also clearly observed, indicating that the concentration of ions decreases at the interface in the solution without and with $0.13 \mathrm{~g} \mathrm{~L}^{-1}$ PASP (Figs. $5 \mathrm{~d}$ and $5 \mathrm{~d}^{\prime}$ ); however, this phenomenon is not observed in the solution with $6.66 \mathrm{~g} \mathrm{~L}^{-1}$ PASP (Fig. $5 \mathrm{~d}^{\prime \prime}$ ) because of the low current and the formation of the complexes.

As shown in Fig. 6, the radius and depth of the pit in the solution with $0.13 \mathrm{~g} \mathrm{~L}^{-1}$ PASP (Fig. 6C1) was much lower than those in the solution without PASP (Fig. 6B1), and there are few pits on the electrode surface in the solution with $6.66 \mathrm{~g} \mathrm{~L}^{-1}$ PASP (Figs. 6D and 6D1), indicating that PASP inhibited pitting corrosion and the inhibitive ability was enhanced with the increase of $c_{\text {PASP }}$ even at an applied potential approximately $600 \mathrm{mV}$ higher than $E_{\text {corr }}$.

As shown in Fig. 7, metallic oxide were formed on the electrode surface because $\mathrm{Ni}, \mathrm{Cr}$, and $\mathrm{O}$ are observed on the electrode surface after anodic dissolution. Because the content of $\mathrm{O}$ element is much 
higher after anodic dissolution, the oxide film is formed much more easily in solution with PASP than that without PASP. PASP anions may have entered the oxide film defects to form a PASP metal complex (PASP-M complex), ${ }^{21}$ thereby sealing the defects, and thus the surface film was formed more easily and it became denser with the increase of $c_{\text {PASP. }}$ This is why the current decreases (Figs. 3-5) and the pitting inhibition ability was enhanced (Fig. 6) with the

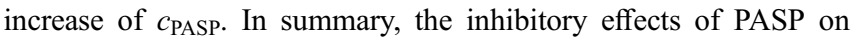
Inconel ${ }^{\circledR} 600$ may be caused by the adsorption of PASP and the formation of a PASP-M complex. ${ }^{15}$

\section{Conclusions}

An electrochemical method was used in conjunction with digital holography to investigate the inhibitory effects of PASP on Inconel ${ }^{\circledR}$ 600 in $0.04 \mathrm{M} \mathrm{HCl}$, and the anodic dissolution processes were observed in situ by digital holography. The following conclusions were drawn.

1. PASP is an anodic inhibitor and it inhibits the pitting corrosion.

2. $E_{\text {corr }}$ shifts positively and $\eta$ increases with increasing $\mathrm{c}_{\mathrm{PASP}}$. The highest $\eta$ of $84.13 \%$ is obtained at $6.66 \mathrm{~g} \mathrm{~L}^{-1}$ PASP.

3. Inhibitory effects may be produced by the adsorption of PASP and the formation of a PASP-M complex, which seal defects in the surface film during the anodic dissolution of Inconel ${ }^{\circledR} 600$, and the effects were enhanced with the increase of $c_{\text {PASP }}$.

\section{Acknowledgments}

This research was supported by the National Natural Science Foundation of China (Nos. 21972059, 51401094, and 21473081), the Priority Academic Programme Development of Jiangsu Higher Education Institutions (PAPD), and the Postgraduate Research \& Practice Innovation Program of Jiangsu Province (KYCX20_2263).

\section{References}

1. Q. Lei, K. Liu, J. Gao, X. Li, H. Shen, and Y. Li, Nucl. Instrum. Methods Phys. Res. B, 404, 185 (2017).

2. Y. I. Kim, H. S. Chung, W. W. Kim, J. S. Kim, and W. J. Lee, Surf. Coat. Technol., 80, 113 (1996).

3. S. Liu, Y. Shao, C. Yan, B. Yuan, L. Li, and C. Wang, Corros. Sci., 169, 108614 (2020).

4. J. Li, M. Ma, Y. H. Lu, and L. Xin, Wear, 346-347, 15 (2016).

5. T. Warchilová, V. Dillingerová, R. Škoda, T. Šimo, O. Matal, T. Vaculovič, and V. Kanický, Spectrochim. Acta, Part B, 148, 113 (2018).

6. C. Chai, Y. Xu, D. Li, X. Zhao, Y. Xu, L. Zhang, and Y. Wu, Prog. Org. Coat., 129, 159 (2019).

7. K. El Mouaden, D. S. Chauhan, M. A. Quraishi, L. Bazzi, and M. Hilali, Int. J. Biol. Macromol., 164, 3709 (2020).

8. Y. Gao, L. Ward, L. Fan, H. Li, and Z. Liu, J. Mol. Liq., 294, 111634 (2019).

9. K. Kamon, N. Uchida, H. Maki, M. Matsui, and M. Mizuhata, Electrochemistry, 89, 111 (2021).

10. I. Sekine, Y. Nakahata, and H. Tanabe, Corros. Sci., 28, 987 (1988).

11. R. Cui, N. Gu, and C. Li, Mater. Corros., 62, 362 (2011).

12. M. Abdallah, S. O. Al Karanee, and A. A. Abdel Fattah, Chem. Eng. Commun., 196, 1406 (2009).

13. D. Wang, J. Xu, J. Wang, and W. Hu, Colloids Surf., A, 608, 125615 (2021)

14. A. Zeino, I. Abdulazeez, M. Khaled, M. W. Jawich, and I. B. Obot, J. Mol. Liq., 250, 50 (2018).

15. L. Yang, Y. Li, B. Qian, and B. Hou, J. Magnes. Alloy, 3, 47 (2015).

16. X. Li, M. Zhang, B. Yuan, L. Li, and C. Wang, Electrochim. Acta, 222, 619 (2016).

17. M. Zhang, B. Yuan, W. Qiong, Y. Zhu, L. Li, and C. Wang, Int. J. Electrochem. Sci., 13, 739 (2018).

18. B. Yuan, C. Wang, L. Li, and S. Chen, Corros. Sci., 58, 69 (2012).

19. B. Yuan, C. Wang, L. Li, and S. Chen, Electrochem. Commun., 11, 1373 (2009).

20. B. Yuan, J. Zhang, G. Gao, L. Li, and C. Wang, Electrochem. Commun., 27, 116 (2013).

21. C. Chai, Y. H. Xu, Y. Xu, S. Liu, and L. Zhang, Eur. Polym. J., 137, 109946 (2020). 